\title{
A consistência da economia de baixo carbono
}

Consistency of low carbon economy

\author{
Marcos Vinicius Godecke
}

Professor no CST em Gestão Ambiental da UFPel-RS

\section{Resumo}

Este estudo utiliza-se de revisão bibliográfica buscando concluir sobre a consistência da Economia de Baixo Carbono a partir da discussão das suas premissas básicas, sobre a existência do aquecimento global e sua origem antrópica, visto não ser objeto de consenso na comunidade científica. O estudo reune fortes indícios da existência do fenômeno e das suas consequências, principalmente nos países em desenvolvimento, caracterizando como relevantes as ações na direção da Economia de Baixo Carbono.

Palavras-chave: mudanças climáticas, aquecimento global, economia de baixo carbono, ceticismo climático

\begin{abstract}
This study uses literature review searching to conclude on the consistency of the Low Carbon Economy from the discussion of their basic assumptions about the existence of global warming and its anthropogenic origin, as it is not the object of consensus in the scientific community. The study reunites strong evidence about the phenomenon existence and its consequences, especially in developing countries, characterizing the actions towards the Low Carbon Economy as relevant.
\end{abstract}

Keywords: climate change, global warming, low carbon economy, climate skepticism 


\section{INTRODUÇÃo}

Não há consenso na comunidade científica sobre a natureza das causas do aquecimento global, tampouco se de fato este aquecimento está ocorrendo. O mainstream dos cientistas defende que a temperatura do planeta está subindo e a principal causa para este fenômeno está no aumento das concentrações dos gases de efeito estufa (GEE) na atmosfera. Dizem que estes aumentos decorrem das atividades humanas, baseadas na queima de combustíveis fósseis, principalmente para a geração de energia e nos transportes, além da queima e derrubada de florestas. Ainda, preveem que as mudanças climáticas decorrentes deste aquecimento serão crescentemente mais trágicas, a menos que os países invistam na chamada economia do baixo carbono, substituindo as fontes energéticas baseadas na queima de hidrocarbonetos e preservem as florestas, entre outras ações.

Por outro lado existe uma parcela de cientistas que questiona a convicção vigente de que o planeta está aquecendo, como Adam (2005). Outros aceitam esta condição, mas questionam a predominância antrópica das causas do aquecimento, atribuindo-o a ciclos naturais, a exemplo de Suguio et al. (2012). São contrários às ações de mitigação, defendendo apenas as ações de adaptação à mudança climática. Tem ainda aqueles que concordam em tudo com o mainstream, mas defendem que os recursos financeiros para a conversão ao baixo carbono, por serem demasiadamente altos, seriam melhor aproveitados em ações sobre problemas mais prementes, como a redução da pobreza, o acesso à água potável e ao combate às epidemias, como a Aids e Malária. É exemplo deste posicionamento o dinamarquês Copenhagen Consensus Center (CCC, 2012).

A disposição política para as ações - leia-se pesados investimentos - em prol da economia de baixo carbono estão intimamente relacionadas ao desfecho deste embate. Muitos interesses econômicos estão envolvidos, tanto de um lado como de outro, de modo que a literatura sobre o tema é prolixa em argumentos, muitas vezes com pouca base científica (HOFFMAN, 2011). O tema é propício para estas discussões, visto que o sistema climático é extremamente complexo e dinâmico, tornando virtualmente impossível as medições em escala global ou a simulação de todas as variáveis em modelos computacionais. Os resultados encontrados pelas pesquisas são necessariamente baseados em probabilidades.

Com base na literatura, num primeiro momento este estudo avalia a questão do aque- cimento e o papel dos GEE antrópicos. A seguir são vistas as consequências do aquecimento com base em cenários. A partir do levantamento destas informações, procura-se vislumbrar o alcance da economia de baixo carbono.

\section{O fenômeno do aQuecimento global}

A partir da constatação do aumento na concentração de GEE na atmosfera terrestre e a preocupação com os problemas que poderiam advir da elevação antrópica da temperatura do planeta, em 1988 o Programa das Nações Unidas para o Meio Ambiente (UNEP - United Nations Environment Programme) - associou-se com a Organização Meteorológica Mundial - (WMO World Meteorological Organization) para a criação do Painel Intergovernamental sobre Mudanças Climáticas (IPCC - Intergovernmental Panel on Climate Change), com a finalidade de avaliar e divulgar informações científicas, técnicas e socioeconômicas relevantes para o entendimento das mudanças climáticas decorrentes deste aquecimento.

$\mathrm{Na}$ Rio 92 foi assinado o tratado internacional de criação da Convenção-Quadro das Nações Unidas para a Mudança do Clima (UNFCCC - United Nations Framework Convention on Climate Change), com o objetivo de estabilizar a concentração de GEE na atmosfera. A UNFCCC passou a apoiar-se nas pesquisas patrocinadas pelo IPCC para a obtenção de informações técnicas capazes de instrumentalizar os encontros entre os países, chamados Conferência das Partes (COP), com vistas à definição de limites de emissões. $\mathrm{O}$ principal resultado alcançado foi o Protocolo de Quioto, assinado em 1997 na COP-3, pelo qual os países signatários comprometeram-se a, até o final de 2012, reduzir suas emissões aos níveis de 1990 (ONU, 1997). Na COP-18 (Doha, 2012), com a participação de representantes de 193 países, foi estabelecido um segundo período de compromisso, de 2013 a 2020, nos moldes do acordo original, desta feita para a redução de $18 \%$ das emissões, comparativamente ao ano de 1990.

Apesar das limitações impostas pela complexidade do sistema climático e as múltiplas interações que determinam seu comportamento, a evolução da simulação e análise dos processos físicos têm promovido avanços na interpretação do passado climático e na capacidade de projetar mudanças futuras. Desde a sua criação, o IPCC produziu quatro grandes publicações atualizando estas avaliações - 1990, 1995, 2001 e 2007 - e está 
preparando um quinto informativo, para publicação em 2014. Os cientistas climáticos estão divididos em três grupos de trabalho: o primeiro (WGI) investiga as bases científicas; o segundo (WGII), os impactos, adaptação e vulnerabilidade; e o terceiro (WGIII), a mitigação das mudanças climáticas (IPCC, 2012).

O clima terrestre é resultado da energia proveniente do Sol e da capacidade da superfície e atmosfera terrestres em absorver, emitir e refletir esta energia. Entre os fatores que influenciam o clima estão a concentração de GEE, partículas de origem vulcânica, aerossóis, albedos de superfície, além das condições da camada de ozônio e concentração de nuvens. Estes fatores produzem forçamentos radiativos no sistema climático (SOLOMON et al., 2007).

Enquanto alguns GEE possuem origem natural e antropogênica, outros são resultados exclusivos da atividade humana. $\mathrm{O}$ forçamento radiativo de cada GEE durante um período de tempo é determinado pela sua concentração atmosférica durante o tempo considerado - resultado líquido das emissões e eliminações - e sua efe-

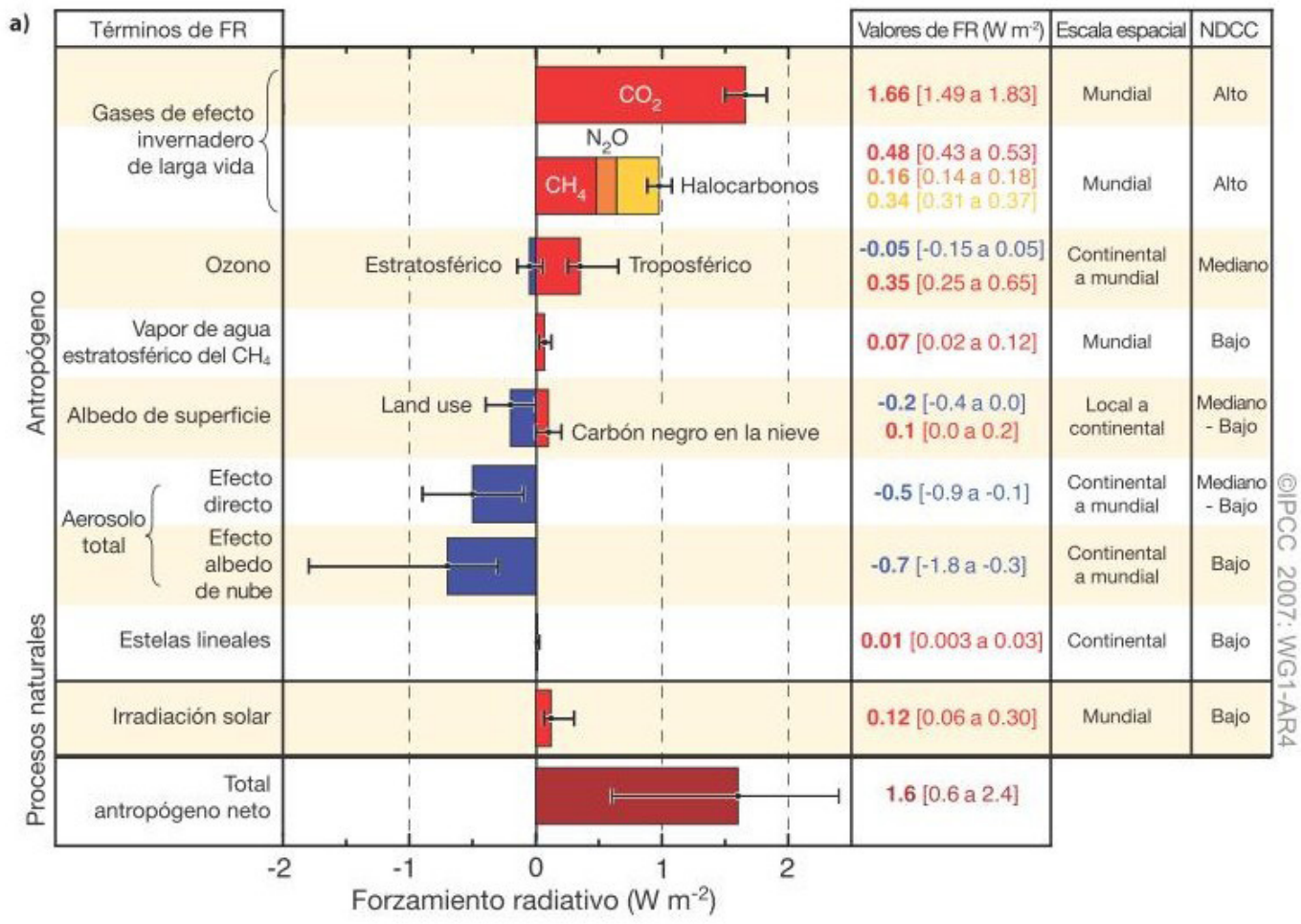

b)

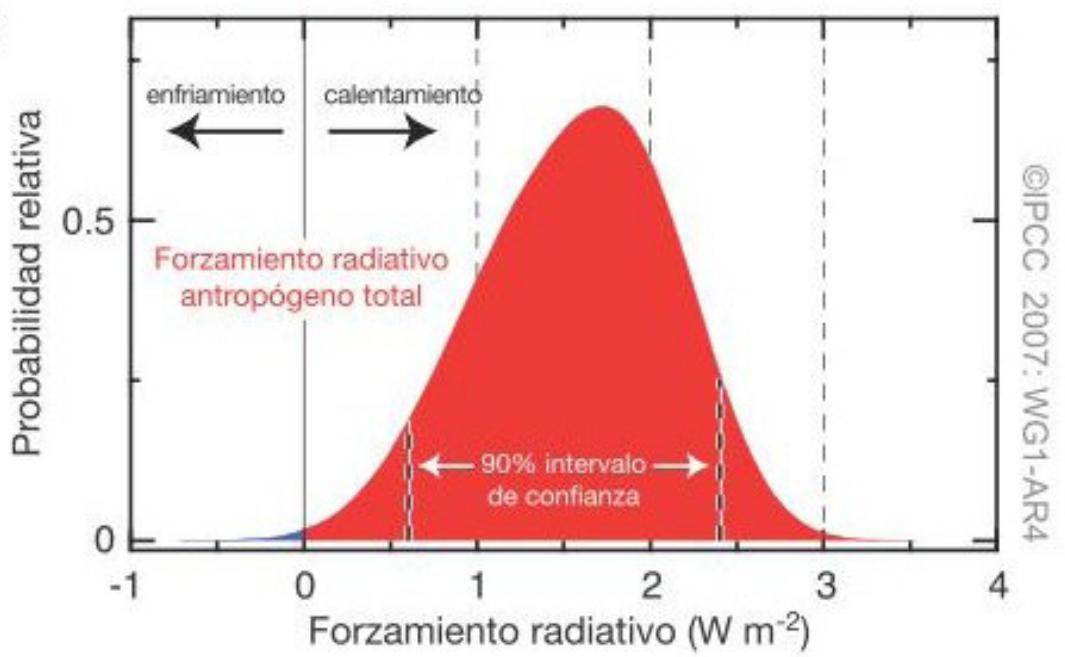

Figura 1 - Forçamento Radiativo médio anual (a) e distribuição de probabilidades (b) em 2005

Fonte: Forster et al., 2007, apud Salomon et al., 2007, p.33. 
tividade em modificar o equilíbrio radiativo. A taxa de eliminação varia em função do nível de concentração e das propriedades atmosféricas, como a temperatura e condicionantes químicas existentes. O dióxido de carbono (CO2), o metano (CH4) e o óxido nitroso (N2O) são chamados GEE de longa vida, pois são quimicamente mais estáveis e persistem na atmosfera durante décadas ou séculos, influenciando o clima no longo prazo. Os gases de vida curta, como o monóxido de carbono (CO) e o dióxido de enxofre (SO2) são mais reativos em processos oxidativos. Na estratosfera o ozônio, importante GEE, é eliminado por reações químicas com substâncias de produção antrópica como os clorofluorcarbonetos (CFC) (SALOMON et al., 2007).

A Figura 1 apresenta o forçamento radiativo médio mundial e seu intervalo de probabilidade de $90 \%$ para o ano de 2005, para vários agentes e mecanismos.

$\mathrm{Na}$ Figura 1 as colunas à direita apresentam os valores de forçamento radiativo diferenciados em processos antropogênicos e naturais, além da extensão geográfica típica do forçamento e o nível de confiança obtido pelas pesquisas científicas (LOSU - level of scienti $\square$ c understanding). Os valores de $\mathrm{CH} 4, \mathrm{~N} 2 \mathrm{O}$ e hidrocarbonetos halogenados estão apresentados de forma associada. Outros fatores de forçamento não foram incluídos na Figura 1 devido ao baixo LOSU. O ozônio, enquanto na troposfera atua como GEE, na estratosfera reflete os raios solares, atuando como redutor do forçamento radiativo. $\mathrm{O}$ uso da terra em atividades antrópicas resulta em aumento do albedo, atuando como componente de resfriamento. Em efeito contrário, a perda da cor branca na neve resulta em aumento do aquecimento. Nos aerossóis foram considerados os efeitos diretos sulfatos (SO4) e carbonos orgânicos - e o albedo das nuvens. Os aerossóis naturais resultantes das erupções vulcânicas, resfriadores, não foram incluídos na Figura 1 devido ao seu caráter esporádico. Não foram incluídos outros efeitos derivados da aviação sobre a atmosfera além das fumaças de aviões (estelas lineales). O somatório dos efeitos - antropogênicos e naturais, de resfriamento e aquecimento - resultou em 1,6 $\mathrm{W}$ m-2 para o ano de 2005. Observa-se que é pequena a relevância do aquecimento decorrente do aumento nos níveis de irradiação solar quando comparada com a ação dos GEE. A Figura 1 (b) demonstra as distribuições de probabilidades considerando-se as margens de erro de cada forçante, sendo que os aerossóis, pelo baixo LOSU, ampliam significativamente a amplitude da distribuição (FORSTER et al., 2007;
SALOMON et al., 2007).

A relação do forçamento radiativo com as alterações climáticas não é simples. No caso dos GEE, além da evolução das concentrações ao longo do tempo, também a distribuição espacial e o tempo de vida de cada gás precisa ser considerada nas análises. A determinação do potencial de aquecimento global (GWP - Global Warming Potential) - é uma forma de relacionar o forçamento radiativo de cada GEE com o seu tempo de permanência na atmosfera, permitindo o estabelecimento de uma relação relativa entre eles. Para esta relação foi atribuído ao GWP do $\mathrm{CO} 2$ o valor um (1) e, a partir deste parâmetro, relacionados os GWP dos demais GEE. O valor do GWP de cada gás varia acompanhando o seu ciclo de vida: por exemplo, o GWP do $\mathrm{CH} 4$ para 100 anos é 25 . Se o tempo considerado fosse 20 anos ou 500 anos, os resultados seriam de 72 e 7,6, respectivamente (GOLDEMBERG, 1998; FORSTER et al., 2007).

A partir destas relações é possível o cálculo da concentração atmosférica do conjunto dos GEE - em partes por milhão ( $\mathrm{ppm}$ ) ou partes por bilhão (ppb) - em termos da concentração equivalente de $\mathrm{CO} 2 \mathrm{e}$, por conseguinte, o forçamento radiativo do conjunto destes gases. Enquanto a quarta publicação do IPCC (2007) utiliza preferencialmente o conceito de forçamento radiativo, o relatório Stern Review (2006) - baseado na terceira publicação do IPCC e em publicações posteriores - utiliza principalmente o conceito de $\mathrm{CO} 2$ equivalente - $\mathrm{CO} 2 \mathrm{e}$. Segundo Stern et al. (2006) o aquecimento combinado dos seis gases contemplados pelo Protocolo de Quioto - CO2, CH4, N2O, hidrofluorcarbonos (HFC), perfluorcarbonos (PFC) e hexafluoreto de enxofre (SF6) - estava em 430 ppm de CO2e, com crescimento de 2,6 ppm ano-1. Esta medida contemplava medições dos efeitos radiativos do momento da medição, sem considerar os tempos de vida dos gases na atmosfera.

Porém, as informações pontuais sobre a situação dos forçantes climáticos num dado momento e a importância relativa dos GEE de longa vida - entre os forçantes - para provocar alterações no sistema climático, não são suficientes. Delas podem resultar questionamentos sobre a importância absoluta dos GEE nas alterações climáticas, ponderados os seus níveis de concentração atmosférica. A Figura 2 é particularmente sugestiva como resposta para esta questão. Nela são apresentadas as concentrações atmosféricas dos três principais GEE, relacionando-as aos níveis de temperatura e extensão das camadas de gelo na Terra nos últimos 650 mil anos. As 


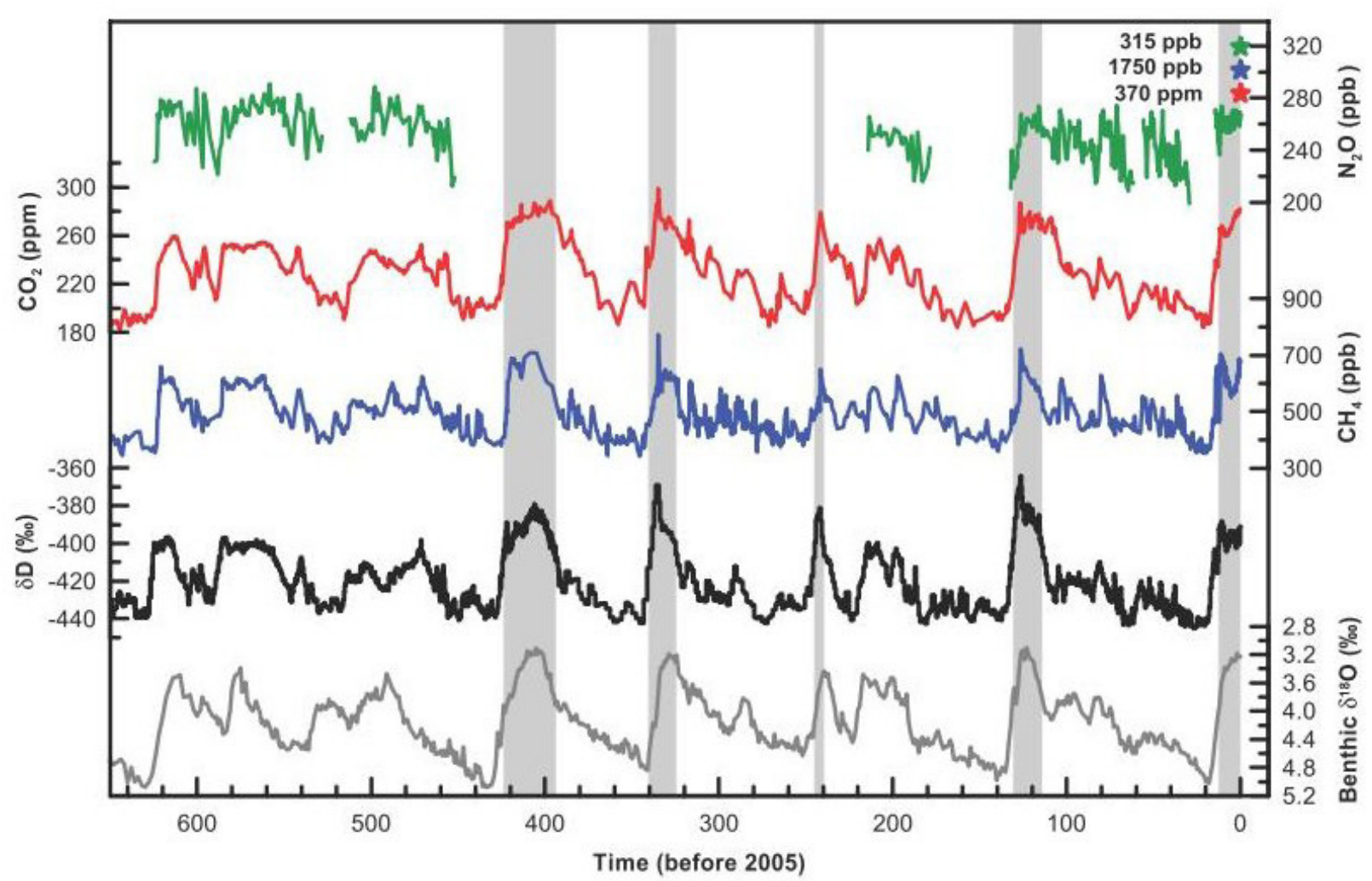

Figura 2 - Dados de testemunhos de gelo glaciais e interglaciais dos 650 mil anos anteriores a 2005.

Fonte: Jansen et al., 2007, p.444

concentrações atmosféricas de CO2 (vermelho), CH4 (azul), e N2O (verde), assim como o deutério ( $\square \mathrm{D}$, preto) foram obtidas a partir da análise de testemunhos de gelo coletados na Antártica e em medições atmosféricas recentes. O deutério é utilizado como proxy da temperatura local. As variações nos níveis bentônicos de $\mathrm{d} 18 \mathrm{O}$ (cinza) são proxy da extensão das geleiras: quanto menor o nível de d180, maior a extensão das geleiras. As barras verticais sombreadas indicam os últimos períodos interglaciais. Observa-se que o período interglacial atual não é incomum no contexto dos últimos 650 mil anos. As estrelinhas verde, azul e vermelha indicam as concentrações dos respectivos GEE no ano 2000 (JANSEN et al., 2007).

A forte influência dos GEE entre os forçantes climáticos, apresentada na Figura 1, combinada com a estreita correlação entre os períodos em que o planeta esteve mais quente (períodos interglaciais) e os picos nos níveis de GEE, apresentados na Figura 2, permitem estabelecer uma relação de causa e efeito entre o aumento na concentração de GEE e o aquecimento global.

A Figura 3 permite relacionar o nível da concentração atmosférica dos três principais GEE com os seus respectivos forçantes radiativos (FR) nos últimos 20.000 anos. Combina a evolução nas concentrações de CO2, NH4 e N2O nos últimos 20 mil anos anteriores a 2005 com o correspondente forçamento radiativo, reconstituídos a partir de testemunhos de gelo antártico - hemisfério sul (SH) - e da Groenlândia - hemisfério norte $(\mathrm{NH})$, neve granular e medições atmosféricas diretas. As barras cinza nos painéis (a), (b) e (c) mostram os níveis de variabilidade naturais reconstruídos durante os últimos 650 mil anos. A taxa de crescimento do FR é apresentada no painel (d) para os últimos 20 mil anos (linha preta) e nos últimos 2 mil anos (linha vermelha). A idade foi calculada com dados que variam desde aproximadamente 20 anos para sítios com grande acumulação de neve até aproximadamente 200 anos para locais com pouca acumulação. A flecha mostra qual seria o pico da taxa de crescimento do forçamento radiativo correspondente às variabilidades naturais dos três gases citados. A Figura 3 evidencia um grande crescimento tanto na concentração como no forçamento radiativo dos três principais GEE no passado recente.

Ainda relacionando as variações de concentrações com o forçamento radiativo, a Tabela 1 explicita que "passado recente" é este, ao comparar os níveis de concentrações existentes no período pré-industrial - tomado o ano de 1750 como referência - com o ano de 2005 e ainda o crescimento recente, de 1998 a 2005. 

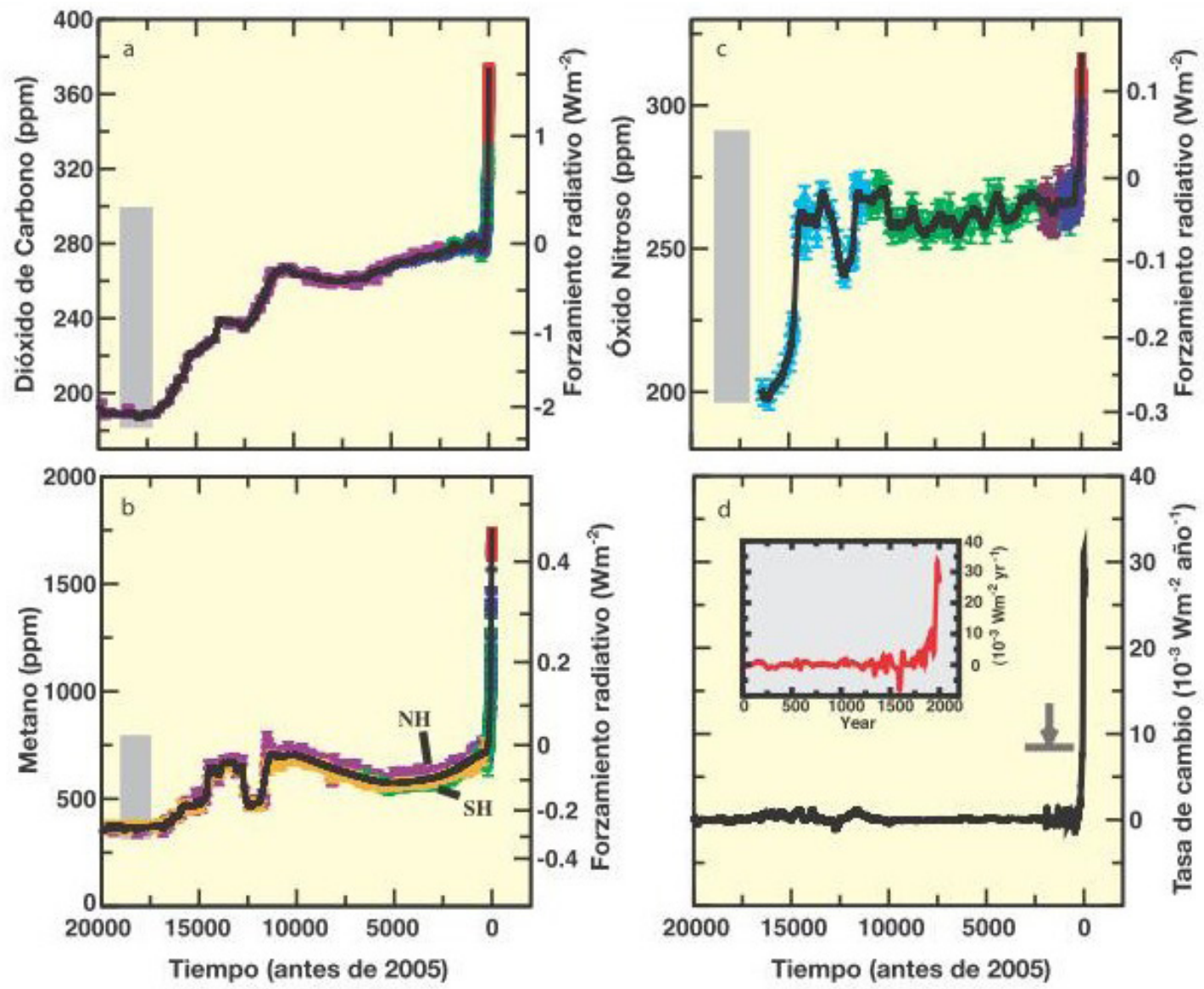

Figura 3 - A evolução nos últimos 20.000 anos na concentração atmosférica de GEE e sua relação com o forçamento radiativo Fonte: Jansen et al., 2007, apud Solomon, 2007, p.25

Tabela 1 - Variações nas concentrações e forçamento radiativo de GEE entre 1998 e 2005

\begin{tabular}{l|c|c|c|cc}
\cline { 2 - 6 } & \multicolumn{3}{c|}{ Concentrações e suas variações $^{1}$} & \multicolumn{2}{c|}{ Forçamento radiativo $^{1}$} \\
\hline $\begin{array}{l}\text { Gases de } \\
\text { efeito estufa }\end{array}$ & $\begin{array}{l}\text { Níveis pré- } \\
\text { industriais }\end{array}$ & 2005 & $\begin{array}{c}\text { Variação desde } \\
1998\end{array}$ & $\begin{array}{c}2005 \\
\left(\mathrm{~W} \mathrm{~m}^{-2}\right)\end{array}$ & $\begin{array}{c}\text { Variação } \\
\text { desde 1998 }\end{array}$ \\
\hline $\mathrm{CO}_{2}$ & $278 \mathrm{ppm}$ & $379+/-0,65 \mathrm{ppm}$ & $+13 \mathrm{ppm}$ & 1,66 & $+13(\%)$ \\
\hline $\mathrm{CH}_{4}$ & $715 \mathrm{ppb}$ & $1774+/-1,80 \mathrm{ppb}$ & $+11 \mathrm{ppb}$ & 0,48 & - \\
\hline $\mathrm{N}_{2} \mathrm{O}$ & $270 \mathrm{ppb}$ & $319+/-0,12 \mathrm{ppb}$ & $+5 \mathrm{ppb}$ & 0,16 & $+11(\%)$ \\
\hline
\end{tabular}

Fonte: Forster et al., 2007, p. 141. Nota: (1) nível de confiança de $90 \%$

Tabela 2 - Concentrações e incrementos dos principais gases de efeito estufa após o ano de 1750

\begin{tabular}{|c|c|c|c|}
\hline & $\mathrm{CO}_{2}(\mathrm{ppm})$ & $\mathrm{CH}_{4}(\mathrm{ppb})$ & $\mathbf{N}_{2} \mathbf{O}(\mathrm{ppb})$ \\
\hline Abundância global em 2011 ${ }^{(1)}$ & $390,9+/-0,1$ & $1813+/-2$ & $324,2+/-0,1$ \\
\hline Abundância em 2010 em relação a 1750(2) & $140 \%$ & $259 \%$ & $120 \%$ \\
\hline Incremento absoluto 2010-2011 & 2 & 5 & 1 \\
\hline Incremento relativo $2010-2011$ & $0,51 \%$ & $0,28 \%$ & $0,31 \%$ \\
\hline Média anual de incremento absoluto entre 2001 e 2011 & 2 & 3,2 & 0,78 \\
\hline
\end{tabular}

Fonte: WMO (2012b) Notas: (1) Nível de confiança de 95\%. (2) Para o ano de 1750 foram assumidas as concentrações de 280 ppm para o $\mathrm{CO} 2,700$ ppb para o $\mathrm{CH} 4$ e 270 ppb para o N2O. 
Enquanto Forster et al. (2007) estudaram a evolução da concentração atmosférica dos principais GEE dos níveis pré-industriais até 2005, os relatórios da WMO trazem esta comparação até o ano de 2011. O oitavo boletim anual WMO Global Atmosphere Watch (GAW)1, de novembro de 2011, trouxe os dados apresentados na Tabela 2, mostrando agravamento nas concentrações em relação à Forster et al. (2007). Além das concentrações dos três principais GEE em 2011, a Tabela 2 apresenta o percentual de incremento destas concentrações em relação à era pré-industrial e seus incrementos absolutos e relativos entre 2010 e 2011, além da média anual dos incrementos no período de 2001 a 2011. Ainda relacionando as variações de concentrações de GEE com o forçamento radiativo, os relatórios da WMO comparam os níveis de concentrações existentes no período pré-industrial - tomado o ano de 1750 como referência - até o ano de 2011. O oitavo boletim anual WMO Global Atmosphere Watch (GAW) ${ }^{2}$, de novembro de 2011, trouxe os dados apresentados na Tabela 2. Além das concentrações dos três principais GEE em 2011, a Tabela 2 apresenta o percentual de incremento destas concentrações em relação à era pré-industrial e seus incrementos absolutos e relativos entre 2010 e 2011, além da média anual dos incrementos no período de 2001 a 2011.

Segundo OECD (2012) as concentrações acumuladas destes três gases, mais os outros três que compõem o rol de gases controlados pelo Protocolo de Quioto - HFC, PFC e SF6 - em 2008 atingiram 428 ppm de CO2e.

A abundância de GHG na atmosfera vem sendo acompanhada de forma abrangente pela americana National Oceanic and Atmospheric Administration (NOAA) desde 1979, através de uma rede global de monitoramento ${ }^{3}$. Em 2004 a NOAA passou a divulgar a evolução conjunta das concentrações dos cinco principais GEE - $\mathrm{CO} 2$, $\mathrm{CH} 4, \mathrm{~N} 20$, diclorodifluorcarbono (CFC-12) e o triclorofluormetano (CFC-11) - e outros 15 gases

\footnotetext{
1 A rede do programa GAW é componente do Global Climate Observing System (GCOS), abrangendo parcerias com 80 países para a coleta de dados sobre as mudanças naturais e antrópicas na atmosfera, coletados e distribuídos pela agência meteorológica Japonesa (WMO, 2012a; 2012b)

2 A rede do programa GAW é componente do Global Climate Observing System (GCOS), abrangendo parcerias com 80 paises para a coleta de dados sobre as mudanças naturais e antrópicas na atmosfera, coletados e distribuidos pela agência meteorológica Japonesa (WMO, 2012a; 2012b)

3 As amostras de ar são coletadas através da rede de amostragem NOAA Earth System Research Laboratory (ESRL), com amostras de cerca de 80 sites mundiais de ar limpo, incluindo medições através de postos terrestres, rotas de navios e por aviões NOAA (2012).
}

minoritários, na maioria halogenados, através de um único índice, o Annual Greenhouse Gas Index (AGGI). A partir do referencial AGGI igual a 1 para as concentrações em 1990, o índice atingiu 1,30 em 2011, conforme demonstra a Figura 4.

$\mathrm{Na}$ Figura 4 a evolução do FR dos gases que compõem o AGGI é apresentada diferenciada em seis agrupamentos, cujo somatório das concentrações acusa um aumento de $30 \%$ no período de apenas 21 anos. O FR desses gases, que em 1979 era da ordem de 1,7 W m-2, alcançou em 2011 em torno de $2,8 \mathrm{~W} \mathrm{~m}-2$, sendo que a contribuição dos cinco maiores gases de longa vida: $\mathrm{CO} 2, \mathrm{NH} 4$, N20, CFC-11 e CFC-12, contribuíram com mais de $96 \%$ do incremento do FR após 1750 . Devido ao maior espectro de gases desta análise e por abranger dados mais recentes, comparativamente à OCDE (2012), as concentrações atmosféricas dos GEE acompanhados pelo AGGI atingiram 473 ppm CO2e em 2011 (NOAA, 2012; WMO, 2012b).

A ciência tem procurado acompanhar pari passu as emissões anuais mundiais de GEE. Enquanto no ano 2000 estas emissões estavam estimadas em 42 GtCO2e (STERN et al., 2006), segundo UNEP (2012), por estimativas baseadas em modelagem, em 2010 teriam atingido 49 GtCO2e ou, considerada a margem de erro, entre 48 e $50 \mathrm{GtCO}$ e. A partir de inventários os resultados mostraram-se maiores, mas de maior dispersão: 50,1 GtCO2e (com um nível de confiança de $95 \%$ e uma margem de erro entre 45,6 e 54,6 GtCO2e).

A Figura 5 apresenta as principais contribuições setoriais para as emissões de GEE em nível mundial. Mostra cerca de 35\% das emissões de GEE controlados pelo Protocolo de Quioto como relacionadas à energia; $18 \%$ decorrentes da atividade industrial; $13 \%$ pelos transportes; $11 \%$ pela agricultura; $11 \%$ em função da decomposição e queima de vegetais e turfas; $8 \%$ pelo setor da construção civil; e os restantes $4 \%$ pelo setor de resíduos sólidos e líquidos. É preciso considerar que uma melhor gestão de resíduos, com otimização da reciclagem, compostagem e recuperação energética, além de reduzir as emissões do setor, atua indiretamente para as reduções dos demais setores: indústrias, energia e transportes. Também com base no JRC/EDGAR, UNEP (2012) estima a participação relativa, em 2010, dos seis gases acompanhados pelo PQ: CO2 (76\%), CH4 (16\%), N2O (6\%) e os F-Gases - PFC, HFC e SF6 (2\%).

Especificamente em relação ao dióxido de carbono, parte das emissões é absorvida pelos 


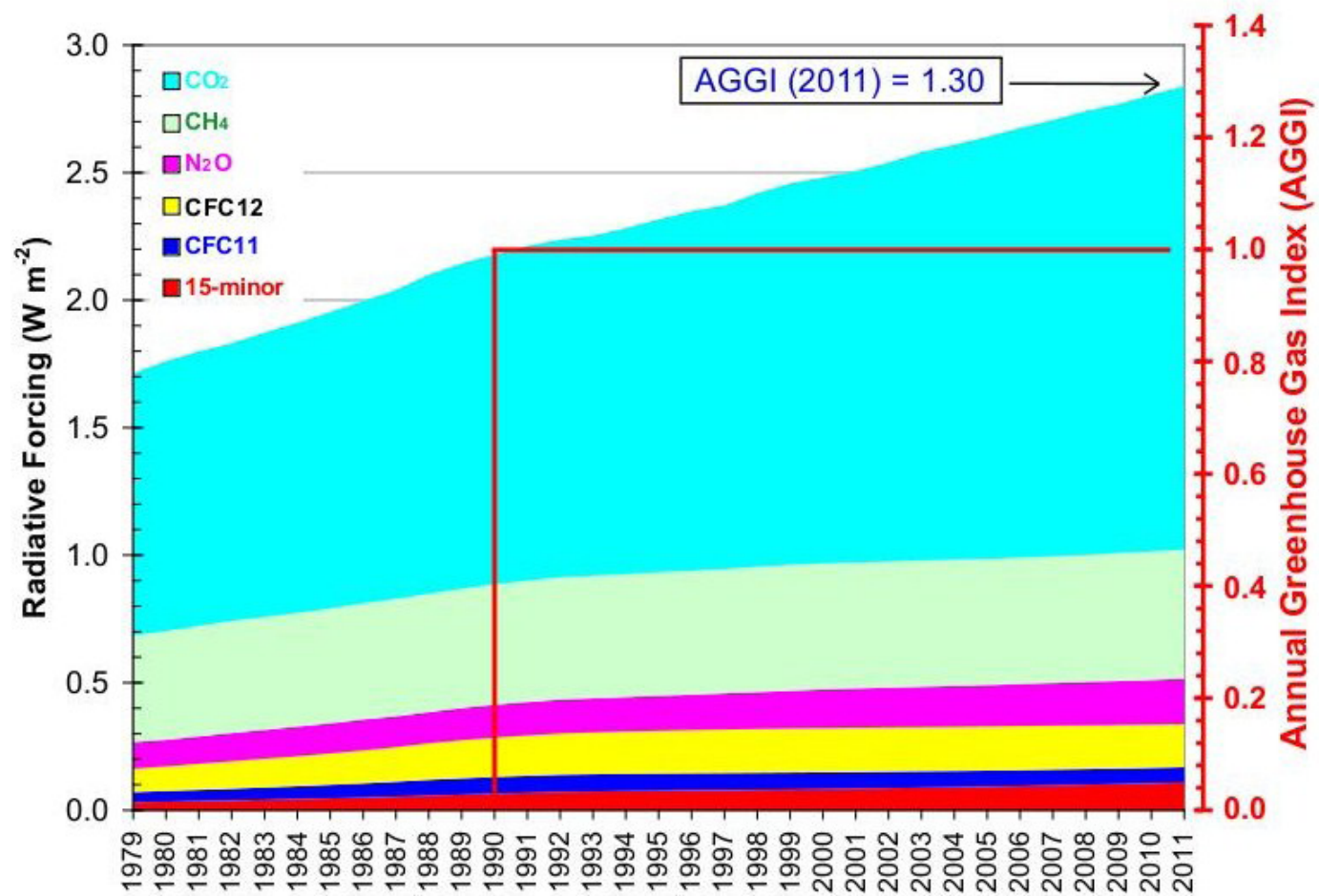

Figura 4 - Evolução no forçamento radiativo comparativamente ao ano de 1750 (linha de base)

Fonte: NOAA (2012, p.5)

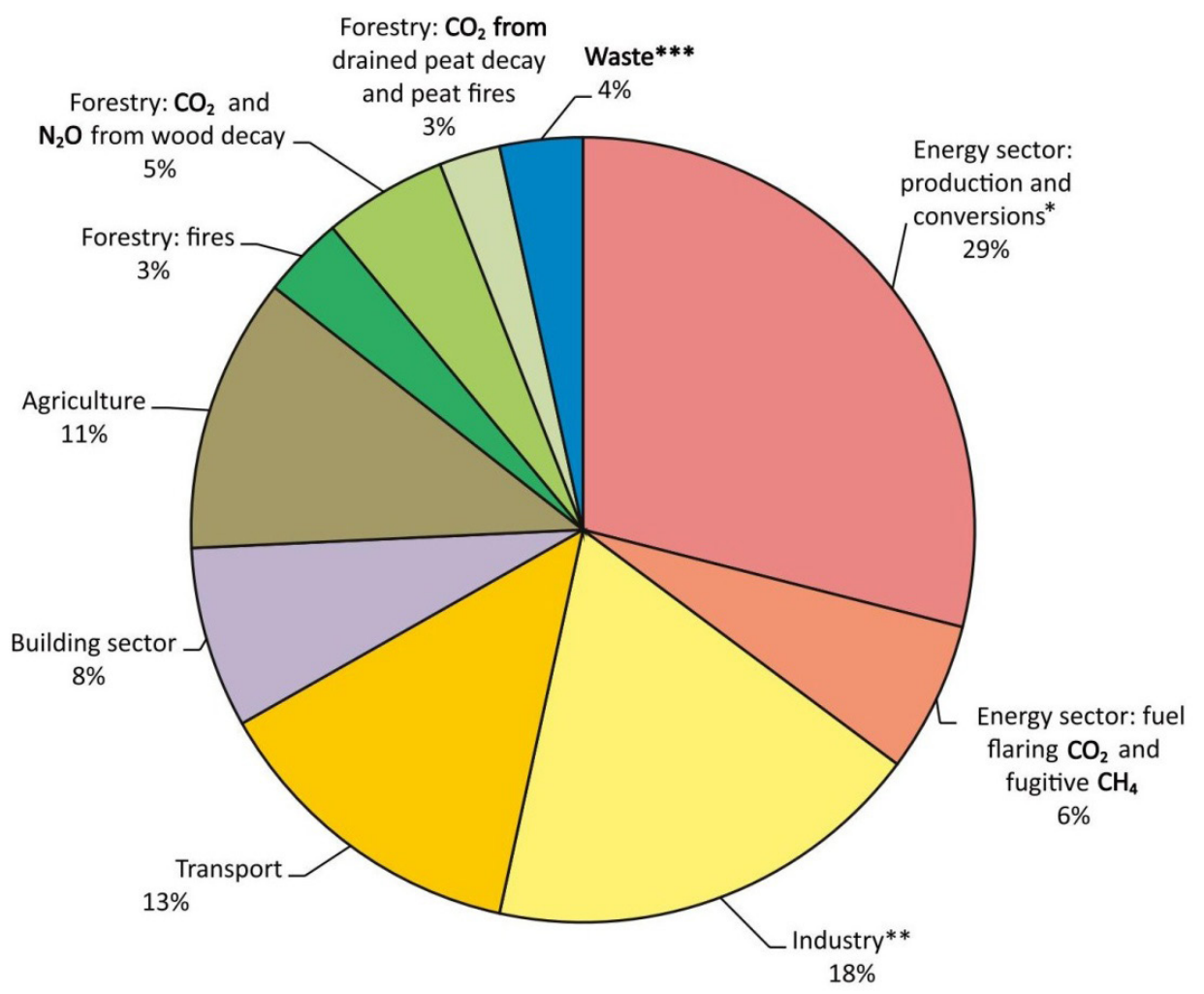

Figura 5 - Emissões globais de gases de efeito estufa em 2010 por setor

Fonte : JRC/EDGAR. 2012,APU ( O banco de dados Emission Database for Global Atmospheric Research (EDGAR) calcula as emissões dos gases abrangidos pelo Protocolo de Quioto, por país e por setor (JRC, 2012).

Notas: * Geração energética e refinarias; ** inclui emissões não energéticas; *** inclui as emissões de esgotos e efluentes 
Tabela 3 - Estimativas de fluxos de carbono, em GtCO2 ano-1

\begin{tabular}{l|c|c|c}
\hline & Anos 1980 & Anos 1990 & Período 2000-2005 \\
\hline Aumento atmosférico & $12,1+/-0,4$ & $11,7+/-0,4$ & $15,0+/-0,4$ \\
\hline Emissões de $\mathrm{CO}_{2}$ fóssil & $19,8+/-1,1$ & $23,5+/-1,5$ & $26,4+/-1,1$ \\
\hline Fluxo líquido oceano-atmosfera & $-6,6+/-2,9$ & $-8,1+/-1,5$ & $-8,1+/-1,8$ \\
\hline Floxo líquido terra-atmosfera & $-1,1+/-3,3$ & $-3,7+/-2,2$ & $-3,3+/-2,2$ \\
\hline
\end{tabular}

Fonte: Solomon et at., 2007, p. 26, adaptada pelo autor

Notas: valores positivos correspondem a fluxos positivos, valores negativos a fluxos negativos (sumidouros); as emissões de 2004 e 2005 se baseiam em cálculos aproximados; devido a falta de estudos disponíveis para o fluxo líquido terra-atmosfera, os níveis de certeza são de 65\%; as emissões de CO2 fóssil incluem as derivadas da produção, distribuição e consumo de combustíveis fósseis e a produção de cimento.
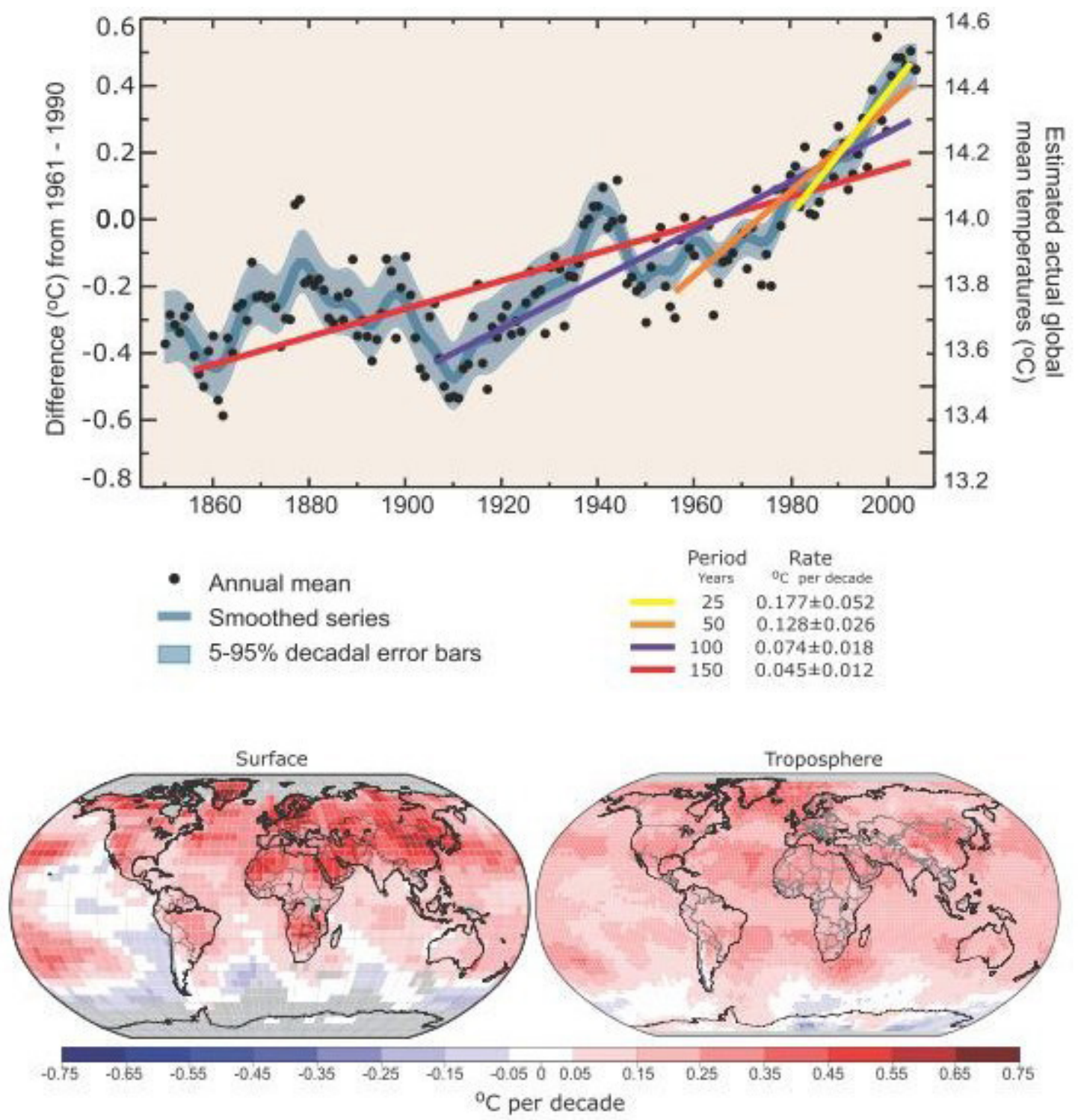

Figura 6 - Medições e tendências da temperatura mundial após 1860

Fonte: Trenberth et al., 2007, p.253 
vegetais e oceanos. A Tabela 3 dimensiona estes fluxos. Porém, como esta capacidade de absorção é limitada, na medida em que ocorram aumentos persistentes nas emissões de $\mathrm{CO} 2$ fóssil, o hiato entre as emissões e os fluxos líquidos oceano-atmosfera e terra-atmosfera tende a aumentar.

A emissão de CO2 informada na Tabela 3 para o período $2000-2005(26,4+/-1,1$ GtCO2 ano-1) está coerente com a publicada por Stern et al. (2006), relacionada com o uso da energia. Seu crescimento segue significativo, pois segundo OECD (2011), no ano de 2010 as emissões do setor de energia atingiram a marca de 30,6 GtCO2, apesar dos efeitos da crise econômica mundial ainda fazerem-se sentir naquele ano.

Paralelamente à análise dos aumentos de FR relacionados às emissões/concentrações de GEE na atmosfera está o acompanhamento das variações na temperatura da Terra, apresentadas na Figura 6. A parte superior da Figura 6 apresenta as médias anuais das medições da temperatura mundial sinalizados por pontos negros. A linha irregular azul é formada pelas variações destas temperaturas na média móvel decenal. A faixa sombreada mostra o nível de confiança de $95 \%$ para a média móvel decenal. As retas coloridas mostram as tendências de comportamento das variações de temperaturas, considerados os períodos de 25, 50, 100 e 150 anos. A escala da esquerda mostra a diferença das temperaturas em relação à variação ocorrida entre os anos de 1961 e 1990 e a escala da direita a temperatura média global observada, ambas em ${ }^{\circ} \mathrm{C}$. O aumento total da temperatura do período de 1859 a 1899 até o período de 2001 a 2005 foi de $0,76^{\circ} \mathrm{C}+/-0,19^{\circ} \mathrm{C}$. $\mathrm{O}$ mapa-múndi da esquerda (parte inferior da Figura 6) mostra a variação da temperatura na superfície e o da direita, as variações de temperatura na troposfera - $10 \mathrm{~km}$ de altitude - medidas por satélites. É mostrado o incremento médio da temperatura por decênio, entre 1979 e 2005 . As áreas em cinza indicam dados incompletos. No território brasileiro, na média decenal entre 1979 e 2005, as temperaturas teriam subido entre 0,15 e $0,35^{\circ} \mathrm{C}$ (TRENBERTH et al., 2007).

Mas, será que estes aumentos de temperatura não decorreram de fatores naturais como o aumento na radiação solar? Utilizando modelos gerais de circulação atmosfera-oceanos -Atmosphere-Ocean General Circulation Models (AOGCM) - em simulações com os forçantes naturais e antropogênicos (a) e apenas naturais (b), em comparação com as anomalias das temperaturas superficiais médias verificadas no planeta $\left({ }^{\circ} \mathrm{C}\right)$, foram obtidos os resultados apresentados na
Figura 7.

$\mathrm{Na}$ Figura 7 as anomalias de temperatura (escala da esquerda) guardam relação com a média das anomalias relativas ao período de 1901 a 1950, formando a linha preta mostrada em (a) e (b). A linha vermelha (a) é resultado da média de 58 simulações produzidas por 14 modelos com forçantes naturais e antropogênicos, mostradas na cor laranja. As linhas cinza na vertical indicam os momentos das maiores atividades vulcânicas do século XX. A linha azul em (b) mostra a média de 19 simulações produzidas por 5 modelos considerando apenas forçantes naturais, mostradas em azul mais claro. A Figura 7 evidencia a importância dos forçantes antropogênicos frente aos naturais.

Este estudo questiona o futuro do movi-
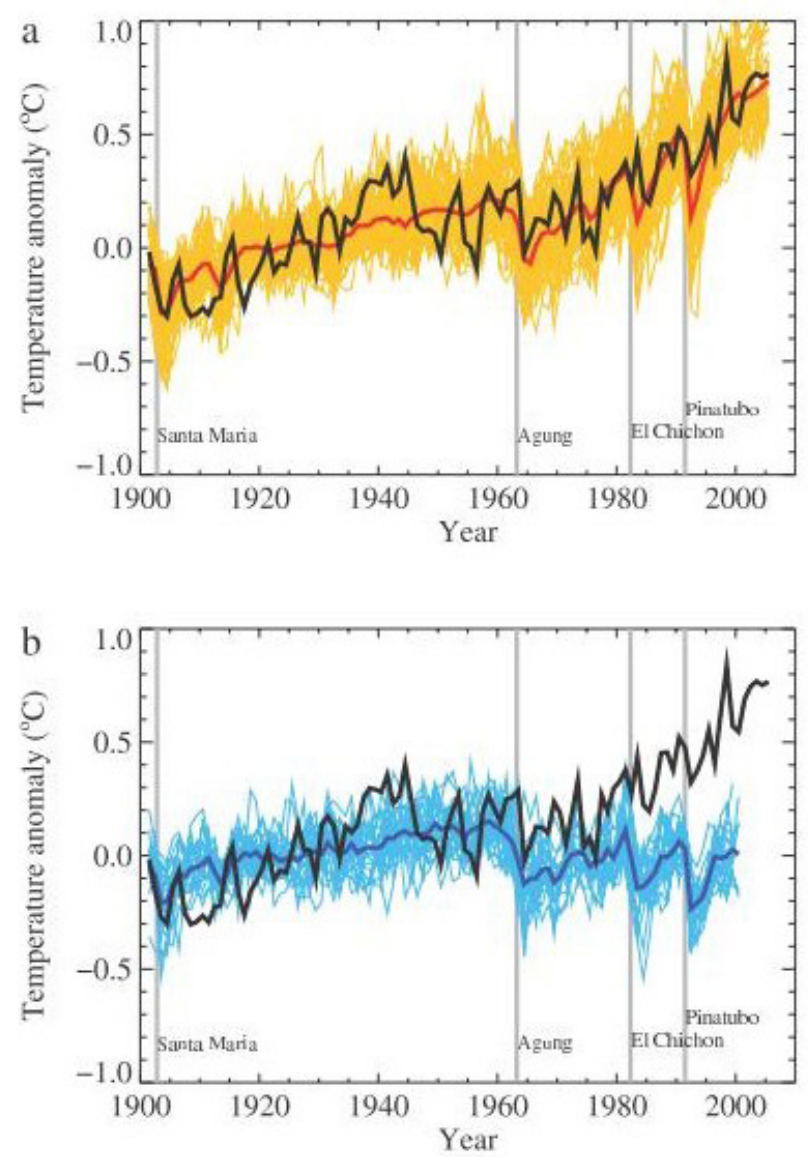

Figura 7 - Simulações de forçantes naturais e antropogênicos relativos ao século $\mathrm{XX}$

Fonte: Hegerl et al., 2007, p.684

mento na direção da economia de baixo carbono e supõe que esta questão estará indiretamente respondida mediante a avaliação da importância dos GEE antropogênicos para as mudanças climáticas. As informações apresentadas nesta seção mostram fortes indícios de que o planeta está aquecendo e com relevante influência dos GEE. Mas, para 
que a análise cresça em consistência é necessária a verificação da tendência do comportamento do clima nas próximas décadas e a amplitude econômica, social e ambiental dessas consequências. Estes são os temas abordados nas duas próximas seções: a primeira verifica as tendências climáticas da Terra e a segunda, as possíveis consequências de um forte aquecimento global.

\section{As TENDÊNCIAS DAS MUDANÇAS CLIMÁtICAS}

Do terceiro relatório do IPCC - 2001 - para o quarto - Assessment Report (AR4), de 2007 ocorreram avanços importantes na ciência das projeções das mudanças climáticas. O programa World Climate Research Programme (WCRP) coordenou ampla ação global para fornecer uma perspectiva multi-modelo das mudanças climáticas, chamada de Coupled Model Intercomparison Project phase three (CMIP3) ou, mais comumente, de multi-model data set (MMD). Apesar de concordar com estes avanços, Meehl et al. (2007) constataram que diferentes métodos mostram consistências em alguns aspectos dos seus resultados, mas diferem significativamente em outros, em função da natureza e do uso das restrições observacionais; da natureza e design dos modelos utilizados; e das incertezas presentes nos parâmetros de entrada dos modelos. Ao tempo em que informam que ainda não há a definição de um método recomendado como de uso preferencial, destacam a importância das informações sobre os pressupostos, limitações e a sensibilidade dos modelos acompanharem as publicações dos resultados.

Os modelos utilizados apresentam três níveis de complexidade: os chamados modelos climáticos simples - simple climate model (SCM) foram utilizados no AR4 para emular as projeções das futuras alterações climáticas realizadas por modelos mais complexos, permitindo a investigação das diversas implicações das variações de temperatura e do nível do mar em diversos cenários de emissões de GEE; de complexidade intermediária, os Earth System Models of Intermediate Complexity (EMIC) incluem dinâmicas relacionadas com as circulações atmosféricas e oceânicas, além de ciclos biogeoquímicos, porém possuem baixa resolução espacial; por fim, os já referidos modelos AOGCM representam o estado-da-arte nas projeções climáticas (RANDALL et al., 2007).

No AR4 as projeções das elevações de temperatura para o século XXI foram realizadas com base em seis plausíveis cenários, todos desconsiderando políticas mitigatórias nas emissões de GEE.

A Tabela 4 mostra os valores esperados por estes cenários para a média global de temperatura no período 2090-2099 em relação ao período 1980-1999.

Os cenários da Tabela 4 apresentam projeções de valores médios globais, porém os aumentos de temperatura projetados variam significativamente em função da região geográfica, conforme demostra a Figura 8. As linhas de traço contínuo à esquerda da Figura 8 mostram em preto o aquecimento médio verificado até o ano 2000 em relação ao período de 1980 a 1999. A partir do ano 2000 as linhas coloridas apresentam as variações médias de temperatura projetadas pelos cenários B1, A1B e A2, além desta variação para o caso das concentrações de GEE permanecerem nos níveis do ano 2000 (linha roxa). Os outros três modelos estão contemplados nas barras verticais do centro da Figura 8, que contempla o intervalo de confiança das simulações de cada cenário, conforme a Tabela 4. Os mapas à direita contemplam a distribuição das variações de temperatura na superfície do

Tabela 4 - Variações esperadas na temperatura média global em 2090-2099 em relação a 1980-1999, em ${ }^{\circ} \mathrm{C}$

\begin{tabular}{l|c|c}
\hline Cenário & Melhor cálculo & Margem de Probabilidade \\
\hline $\begin{array}{l}\text { Se permanecerem constantes as } \\
\text { concentrações do ano 2000 }\end{array}$ & 0,6 & $0,3-0,9$ \\
\hline Cenário B1 & 1,8 & $1,1-2,9$ \\
\hline Cenário A1T & 2,4 & $1,4-3,8$ \\
\hline Cenário B2 & 2,4 & $1,4-3,8$ \\
\hline Cenário A1B & 2,8 & $1,7-4,4$ \\
\hline Cenário A2 & 3,4 & $2,0-5,4$ \\
\hline Cenário A1F1 & 4,0 & $2,4-6,4$ \\
\hline
\end{tabular}

Fonte: Solomon et al., 2007, p. 72 

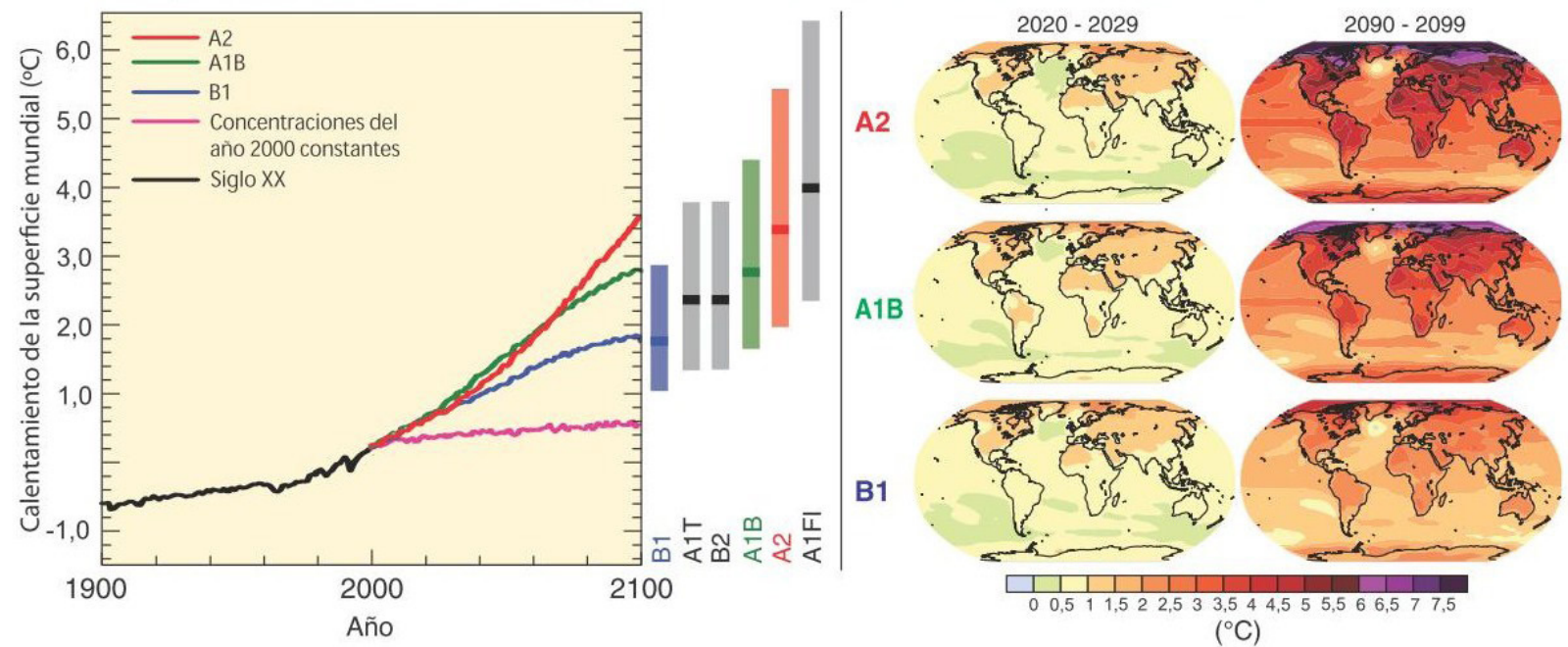

Figura 8 - Projeções do aquecimento de superfície nas diferentes regiões do planeta no século XXI

Fonte: IPCC, 2007, p.46

Planeta para duas décadas distintas - 2020-2029 e 2090-2099 - em três cenários: o de maior elevação no aquecimento (A2), um intermediário (A1B) e o mais otimista (B1).

Com base nas estimativas das concentrações, emissões anuais e crescimento do FR, apresentadas no tópico anterior, publicações recentes procuram estimar a evolução destes parâmetros para as próximas décadas e suas repercussões no crescimento da temperatura do planeta. Segundo OECD (2011), sem políticas ambiciosas de mitigação, as concentrações dos gases controlados pelo $\mathrm{PQ}$ deverão atingir 685 ppm de CO2e em 2050 e mais de 1000 ppm em 2100, quantidades significativamente superiores aos $450 \mathrm{ppm}$ necessários para estabilizar a temperatura num crescimento limitado a $2^{\circ} \mathrm{C}$ em relação a 1750 , meta assumida pelos países na COP-16 - Cancun, 2010 - para cumprimento até 2020 . As previsões são de acréscimos entre $2-2,8^{\circ} \mathrm{C}$ até 2050 e entre 3,7 e $5,6^{\circ} \mathrm{C}$ até o final deste século, comparativamente aos níveis pré-industriais.

Com relação às emissões anuais de GEE, o montante de 49 GtCO2e tido por UNEP (2012) como a melhor estimativa para o ano de 2010 , ficou $14 \%$ superior ao nível de emissões desejado, de $44 \mathrm{GtCO} 2 \mathrm{e}$, para que fosse atingida a meta assumida na COP-16.

No tocante às emissões de $\mathrm{CO} 2$, as análises de cenário de OECD (2011) permitem estimar que sem políticas mais ambiciosas do que as vigentes, as emissões deste gás deverão aumentar mais de $50 \%$ até 2050 , impulsionadas principalmente pelo crescimento estimado em $70 \%$ destas emissões decorrentes do uso de energia fóssil.
Enquanto algumas instituições - IPCC, OECD, UNEP - procuram projetar a situação futura, visando evidenciar a tendência de crescimento significativo da temperatura do Planeta, acompanhando o FR resultante do aumento também significativo das concentrações atmosféricas de GEE, outras publicações - WMO e NOAA limitam-se a acompanhar a evolução histórica deste crescimento. Nestes últimos, a simples projeção de gráficos como o AGGI evidenciam a mesma tendência encontrada pelos primeiros.

Se a temperatura do planeta está crescendo em ritmo acelerado e as medidas mitigadoras adotadas pelos países até o momento mostram-se insuficientes, quais seriam as consequências de um acréscimo de 3 a $4{ }^{\circ} \mathrm{C}$ na temperatura média do planeta até o final deste século?

\section{As CONSEQUÊNCIAS dAS MUdANÇAS CLIMÁticAS}

Como o objetivo desta pesquisa é aquilatar as perspectivas de futuro da economia de baixo carbono, reveste-se de fundamental importância a avaliação sobre as principais mudanças climáticas, sua amplitude, os impactos regionalizados e a repercussão econômica do fenômeno.

Parte integrante do AR4, o relatório "sumário para formuladores de políticas" resume as conclusões do WGII sobre os impactos, adaptação e vulnerabilidade relacionadas ao aquecimento global. Como estes estudos são baseados em estimativas, seus resultados são apresentados em níveis de confiança e probabilidades de ocorrência, seguindo a terminologia apresentada na Tabela 5 
Tabela 5 - Termos utilizados pelo IPCC para descrever as incertezas do entendimento atual sobre as consequências do aquecimento global

\begin{tabular}{l|c|l|c}
\hline \multicolumn{1}{c|}{ Terminologia } & Chance & Terminologia & Probabilidade \\
\hline Muito alto $\left({ }^{* *}\right)$ & 9 em 10 & Praticamente certo & $>99 \%$ \\
\hline Alto $\left(^{* *}\right)$ & 8 em 10 & Muito provável & 90 a $99 \%$ \\
\hline Médio $\left({ }^{*}\right)$ & 5 em 10 & Provável & 66 a $90 \%$ \\
\hline Baixo & 2 em 10 & Improvável & 10 a 33\% \\
\hline Muito baixo & 1 em 10 & Excepcionamente improvável & $<1 \%$ \\
\hline
\end{tabular}

Fonte: Adger et al., 2007, p.29

(ADGER et al, 2007).

$\mathrm{O}$ atual nível do conhecimento sobre a projeção dos impactos das mudanças climáticas abrange as alterações relacionadas com a ocorrência de eventos climáticos extremos, alterações nos recursos hídricos, ecossistemas, produção de alimentos, fibras e produtos florestais. Inclui os impactos nos sistemas costeiros e áreas de baixa altitude, indústria, assentamentos humanos e sociedade, e saúde. As projeções procuram captar as transformações resultantes da interação dinâmica das diversas variáveis climáticas - precipitação, temperatura, concentração atmosférica de GEE, etc. - diferenciadas por região geográfica e nos efeitos, que podem resultar como positivos, negativos ou mistos. Sendo que a amplitude dos efeitos dependerá, em grande parte, da capacidade de mitigação e adaptação de cada país, decorrente da disposição política para as ações, e das limitações impostas pelas suas capacidades econômicas.

Com relação à América Latina, Adger et al.(2007, p.11-16) relaciona impactos decorrentes das mudanças climáticas. Entre eles: (i) a expectativa, até meados do século, da substituição gradual da floresta tropical por savana no leste da Amazônia. A vegetação semiárida tenderá a ser substituída por vegetação de terras áridas. Risco de perda significativa de biodiversidade (**); (ii) nas áreas mais secas, a salinização e desertificação das terras agrícolas. Diminuição da produtividade de algumas culturas importantes e da pecuária, com consequências para a segurança alimentar. Nas zonas temperadas projeta-se um aumento das safras de soja (**); (iii) mudanças nos padrões de precipitação e desaparecimento das geleiras podem afetar de forma significativa a disponibilidade de água para o consumo humano, a agricultura e a geração de energia $\left({ }^{* *}\right)$.

No que tange aos eventos climáticos extremos, ao longo do século XXI é muito provável a ocorrência de alterações nas suas frequências, áreas de abrangência e intensidades, conforme demonstra o Quadro 1.

As pesquisas científicas sobre os efeitos do aquecimento global, resumidas no relatório de Adger et al., 2007, permitem uma visão bastante abrangente dos possíveis impactos do aquecimento global. Outro relatório de publicação à época, Stern (2006), na sua parte II: The Impacts of Climate Change on Growth and Development, apresenta os possíveis impactos relacionados à água, alimentos, saúde, ocupação territorial, ambiente e eventos climáticos extremos - considerando diversos níveis de intensidade, relacionados com cada grau $\left({ }^{\circ} \mathrm{C}\right)$ de elevação na temperatura média mundial, enriquecendo em detalhamentos algumas das informações apresentadas sucintamente nos quadros anteriores, porém sem alterar a sua essência.

Segundo OECD (2011), pesquisas recentes sugerem que os impactos das mudanças climáticas podem ser maiores do que as estimadas pelo AR4. Cita como exemplo as pesquisas de Oppenheimer et al. (2007) e Rahmstorf (2007) sobre maiores níveis de elevação dos mares; e a perda acelerada das camadas de gelo da Groenlândia e geleiras de montanhas que, segundo o Programa de Avaliação de Monitoramento do Ártico - Arctic Monitoring Assessment Programme (AMAP, 2009), podem elevar o nível dos mares em 0,9 a 1,6 metros; cita as pesquisas sobre as emissões extras de metano pelo descongelamento do permafrost, decorrentes do aumento das temperaturas do polo Ártico, como a Shaefer et al. (2011), e as conclusões de que a sensibilidade climática é maior do que a estimada no AR4, de modo que os aumentos de concentração de GEE poderiam elevar a temperatura mais do que anteriormente previsto. $\mathrm{O}$ impacto do derretimento do permafrost pode ser muito significativo, haja vista a pesquisa de Schuur e Abbott (2011) ter concluido que as terras do Ártico contêm 1,7 bilhão de tCO2e, cerca de 
Quadro 1 - Fenômenos extremos, probabilidade de ocorrência e impactos relacionados

\begin{tabular}{|l|l|l|}
\hline Fenômeno & Probabilidade & Principais impactos \\
\hline $\begin{array}{l}\text { Dias e noites mais } \\
\text { quentes; } \\
\text { ondas de calor }\end{array}$ & $\begin{array}{l}\text { Praticamente } \\
\text { certo } \\
\text { minuição em regiões hoje já quentes; mais insetos; derre- } \\
\text { timento de neves; redução da energia para aquecimento e } \\
\text { aumento para refrigeração; mais incêndios florestais; maior } \\
\text { demanda de água; maior mortalidade pelo calor e menor } \\
\text { pelo frio; menor qualidade de vida em regiões hoje já muito } \\
\text { quentes }\end{array}$ \\
\hline Mais chuvas extremas & Muito & $\begin{array}{l}\text { Danos às culturas; erosão do solo; contaminação do abas- } \\
\text { tecimento de água; a escassez de água pode ser atenuada; } \\
\text { aumento do risco de mortes por desastres e doenças; perdas } \\
\text { de infraestrutura e propriedades, comércio, transportes }\end{array}$ \\
\hline $\begin{array}{l}\text { Maior área afetada } \\
\text { pelas secas }\end{array}$ & Provável & $\begin{array}{l}\text { Degradação da terra, queda da produção agrosilvipastoril; } \\
\text { incêndios florestais; escassez de água e alimentos; doenças; } \\
\text { redução do potencial de geração hidrelétrica; migração po- } \\
\text { pulacional }\end{array}$ \\
\hline $\begin{array}{l}\text { Intensificação de ciclo- } \\
\text { nes tropicais }\end{array}$ & Provável & $\begin{array}{l}\text { Queda da produção agrosilvipastoril; danos aos recifes de } \\
\text { corais; aumento do risco de mortes e doenças; perdas de } \\
\text { infra-estrutura e propriedades }\end{array}$ \\
\hline $\begin{array}{l}\text { Aumento da } \\
\text { incidência de } \\
\text { nível } \\
\text { extremamente } \\
\text { alto do mar }\end{array}$ & Provável & $\begin{array}{l}\text { Salinização de águas; aumento do risco de mortes; custos } \\
\text { da proteção costeira; migrações populacionais; perdas de } \\
\text { infraestrutura e propriedades }\end{array}$ \\
\hline
\end{tabular}

Fonte: adaptado de Adger et al., 2007, p.21-22

Nota: (1) O nível extremamente alto do mar depende do nível médio do mar e dos sistemas regionais de tempo. É definido como o 1\% mais elevado dos valores horários do nível do mar observados em uma estação para um determinado período de referência.

quatro vezes o carbono emitido pelas atividades humanas nos tempos modernos e o dobro do que a atmosfera contém atualmente.

O relatório OECD (2011), ao adotar as conclusões do AR4 com relação aos impactos do aquecimento global, destaca que os impactos mais significativos serão sentidos nos países em desenvolvimento, em função das já difíceis condições climáticas em que se encontram; a composição setorial de suas economias, muito dependente dos produtos primários; e sua limitada capacidade econômica para as ações de adaptação. Aprofundando esta percepção, Correa e Comim (2008) estudaram as relações entre as perturbações climáticas e o desenvolvimento humano, encontrando que os choques climáticos afetam e limitam os meios para a expansão do bem-estar das pessoas, além de limitar o exercício da escolha dos estilos de vida por influências de decisões de outros, relacionadas às medidas de mitigação. Também, da preocupação dos cidadãos com as incertezas sobre os impactos futuros das mudanças climáticas nas suas vidas e de seus descendentes. Aqueles autores observam que, como os componentes do bem-estar humano estão inter-relacionados, o efeito da mudança climática sobre um componente reduz a qualidade do outro, causando retrocesso no bem-estar humano como um todo e a diminuição do desenvolvimento humano, principalmente nos países em desenvolvimento, em função das suas localizações geográficas e das condições de vulnerabilidade pré-existentes, como a dependência de recursos naturais e capacidade limitada de adaptação, em face dos níveis de pobreza, baixo acesso a serviços básicos e incipiente nível das instituições.

A produção do relatório Economia do 
Clima no Brasil, elaborado em 2010, reuniu uma equipe interdisciplinar de diversas instituições, com o objetivo de analisar sob o ponto de vista econômico os impactos das mudanças climáticas e o custo das medidas de mitigação e adaptação. $\mathrm{O}$ estudo apontou as regiões Nordeste e Amazônica como as mais vulneráveis, com projeção de perdas entre R\$ 719 bilhões e R \$ 3,6 trilhões em 2050, caso ações as ações não ocorram. Na Amazônia, estima-se que as mudanças climáticas resultariam na redução de $40 \%$ da cobertura florestal na região, substituída pelo bioma savana. No Nordeste, a redução das chuvas causariam perdas agrícolas em todos os estados da região, reduzindo em em $25 \%$ a bovinocultura de corte, entre outras consequências (MARCOVITCH et al. 2010) .

Um forte argumento utilizado pelos céticos refere-se às vantagens do crescimento dos vegetais em atmosferas mais carregadas de CO2. Stern (2006), no seu box 3.4 (p.70), analisa os benefícios decorrentes desta maior concentração e cita a pesquisa de Long et al. (2006), sobre a simulação da duplicação nos níveis de $\mathrm{CO} 2$, mantidas as demais variáveis climáticas próximas às reais. Aquela pesquisa encontrou vantagens de apenas 8 a $15 \%$ no crescimento para culturas que respondem diretamente ao aumento de $\mathrm{CO} 2$ - como trigo, arroz, soja - e nenhum efeito significativo para as espécies não responsivas, como o sorgo e milho. Por outro lado, Stern et al. (2006) mostra a pesquisa de Parry et al. (2004), que encontrou significativo decréscimo na produtividade mundial de cereais pelo incremento da temperatura mundial combinada com pequenos aumentos na concentração de carbono.

\section{Considerações Finais}

O foco deste estudo foi buscar fundamentação científica sobre a existência e a natureza antrópica do aquecimento global, até porque não há consenso na comunidade científica sobre a sua real existência. Das correntes "céticas" de pensamento, anteriormente citadas: negativa da existência do aquecimento, negativa da decorrência antrópica e a não priorização de investimentos para esta mitigação/adaptação. Esta terceira foge ao escopo deste estudo, pois não nega o fenômeno, apenas discute a questão da priorização dos investimentos nas ações de mitigação e adaptação ao aquecimento global, diante de outras necessidades prementes, como o combate à fome. Prega a inteligência destas ações, de modo a possibilitar a canalização de recursos para outras necessidades, circunstância que vem ao encontro das premissas da economia de baixo carbono. As duas primeiras ficam prejudicadas diante do conjunto de evidências trazidas pelos referenciais bibliográficos apresentados neste estudo. A seção dois apresentou resultados de pesquisas sobre a ocorrência do aquecimento, onde o estudo da relação entre os forçantes radiativos evidencia que o aquecimento verificado a partir da revolução industrial, embora tenha a contribuição de uma maior atividade solar, deve-se primordialmente aos GEE. Não satisfeito com as evidências obtidas no acompanhamento da evolução histórica do fenômeno, a seção três avaliou a manutenção da tendência nas próximas décadas, onde as publicações sobre o tema deixam clara esta tendência, mantida o atual rítmo de crescimento nas concentrações dos GEE. Na avaliação da amplitude das consequências do aquecimento global - seção anterior - embora regiões hoje frias possam obter algumas vantagens com o aquecimento, no geral as perdas superam em larga escala estas vantagens, especialmente nos países em desenvolvimento, onde o aquecimento global tende a piorar significativamente as condições de vida, pelo agravamento das condições de acesso à água e alimentos, entre outras consequências negativas.

Ainda, contrapõe-se ao pensamento cético o princípio da precaução, pois, diante dos níveis probabilísticos apresentados pelas pesquisas científicas sobre o problema, seria de grande insensatez os fazedores de políticas públicas, e a sociedade em geral, não o considerarem em suas ações. Este princípio de direito, mesmo visto isoladamente, mostra-se suficiente para justificar o fortalecimento das ações visando o baixo carbono.

Diante do exposto, as iniciativas na direção da economia de baixo carbono resultam necessárias para o controle dos forçantes radiativos de origem antrópica, principal causa do aquecimento global.

\section{Bibliografia}

ADAM, D. Climate change sceptics bet $\$ 10,000$ on cooler world. The Guardian, 19 august 2005. Disponível em: $<$ http://www.guardian.co.uk/environment $/ 2005 / \mathrm{aug} / 19 /$ climatechange.climatechangeenvironment>. Acesso em: 27 nov. 2012.

ADGER, N. et al. Resumen para Responsables de Políticas. In: Mudança do Clima 2007: Impactos, Adaptação e Vulnerabilidade : Contribuição do Grupo de Trabalho II ao Quarto Relatório de Avalia- 
ção do Painel Intergovernamental sobre Mudança do Clima : Sumário para os Formuladores de Políticas. Disponível em: < http://www.ipcc.ch/pdf/reports-nonUN-translations/portuguese/ar4-wg2-spm.pdf $>$. Acesso em 26 nov. 2012.

\section{COPENHAGEN CONSENSUS CENTER (CCC).} Copenhagen Consensus on Climate. Disponível em: <http://www.copenhagenconsensus.com/Projects/ Copenhagen\%20Consensus\%20on\%20Climate. aspx>. Acesso em: 27 nov. 2012.

CORREA, E.; COMIM, F. Impactos Potenciais da Mudança Climática no Desenvolvimento Humano. In: $36^{\circ}$ Encontro Nacional de Economia, 9 - 12 dez. 2008, Salvador (BA). Anais eletrônicos... Salvador.

FORSTER, P. et al. Changes in Atmospheric Constituents and in Radiative Forcing. In: Climate Change 2007: The Physical Science Basis. Contribution of Working Group I to the Fourth Assessment Report of the Intergovernmental Panel on Climate Change. Cambridge, United Kingdom and New York, NY, USA: Cambridge University Press, 2007.

GOLDEMBERG, J. Energia, Meio Ambiente \& Desenvolvimento. São Paulo: Editora da USP, 1998.

HEGERL, G. C. et al. Understanding and Attributing Climate Change. In: Climate Change 2007: The Physical Science Basis. Contribution of Working Group I to the Fourth Assessment Report of the Intergovernmental Panel on Climate Change. Solomon, S., D. Qin, M. Manning, Z. Chen, M. Marquis, K.B. Averyt, M. Tignor and H.L. Miller (eds.). Cambridge, United Kingdom and New York, NY, USA: Cambridge University Press, 2007.

HOFFMAN, A. J. The culture and discourse of climate skepticism. Strategic Organization 9(1) 1-8 , 2011. Disponível em: <http://www.c2es.org/docUploads/climate-skepticism.pdf $>$. Acesso em: 08 nov. 2012.

INTERGOVERNMENTAL PANEL ON CLIMATE CHANGE (IPCC). Homepage institucional, 2012. Disponível em: <http://www.ipcc.ch/index.htm $>$. Acesso em: 15 nov. 2012.

Cambio climático 2007: Informe de síntesis. Contribución de los Grupos de trabajo I, II y III al Cuarto Informe de evaluación del Grupo Intergubernamental de Expertos sobre el Cambio Climático. IPCC, Ginebra, Suiza. Disponível em: < http://www. ipcc.ch/pdf/assessment-report/ar4/syr/ar4 syr sp.pdf >. Acesso em: 24 nov. 2012.

JANSEN, E. et al. Palaeoclimate. In: Climate Change 2007: The Physical Science Basis. Contribution of Working Group I to the Fourth Assessment Report of the Intergovernmental Panel on Climate Change. Solomon, S., D. Qin, M. Manning, Z. Chen, M. Marquis, K.B. Averyt, M. Tignor and H.L. Miller (eds.). Cambridge, United Kingdom and New York, NY, USA: Cambridge University Press, 2007.

JOINT RESEARCH CENTRE (JRC). Total GHG Emissions (CO2, CH4, N2O, HFCs, PFCs, SF6) in 1990, 2000, 2005 and 2008. Disponível em: <http:// edgar.jrc.ec.europa.eu/overview.php\#>. Acesso em: 25 nov. 2012.

MARCOVITCH, J. et al. Economia da Mudança do Clima no Brasil: Custos e Oportunidades. São Paulo: IBEP Gráfica, 2010. Disponível em: $<\underline{\text { http: // }}$ www.colit.pr.gov.br/arquivos/File/Publicacoes/Economia do clima.pdf $>$. Acesso em 9 maio 2013.

MEEHL, G. A. et al. Global Climate Projections. In: Climate Change 2007: The Physical Science Basis. Contribution of Working Group I to the Fourth Assessment Report of the Intergovernmental Panel on Climate Change. Cambridge, United Kingdom and New York, NY, USA: Cambridge University Press, 2007.

\section{NATIONAL OCEANIC AND ATMOSPHERIC} ADMINISTRATION (NOAA). The NOAA Annual Greehouse Gas Index (AGGI). Updated summer 2012. Disponível em: <http://www.esrl.noaa.gov/ gmd/aggi/>. Acesso em: 20 nov. 2012.

\section{ORGANISATION FOR ECONOMIC CO-} -OPERATION AND DEVELOPMENT (OECD). OECD Environmental Outlook to 2050. Climate Change Chapter. Pre-release Version. 2011. Disponível em: <http://www.oecd.org/env/climatechange/49082173.pdf >. Acesso em: 22 nov. 2012.

ORGANIZAÇÃO DAS NAÇÕES UNIDAS (ONU). Protocolo de Quioto. 1997. Disponivel em: $<$ http:// mudancasclimaticas.cptec.inpe.br/ rmclima/pdfs/Protocolo Quioto.pdf >. Acesso em: 24 nov. 2012.

RANDALL et al. Cilmate Models and Their Evaluation. In: Climate Change 2007: The Physical Science Basis. Contribution of Working Group I to the Fourth Assessment Report of the Intergovernmental Panel on Climate Change. Cambridge, United Kingdom and New York, NY, USA: Cambridge Univer- 
sity Press, 2007.

SCHUUR, E. A. G.; ABBOTT, B. Climate Change: High risk of Permafrost Thaw. Nature, 480 (01 December 2011), 32-33.

SOLOMON, S. et al. Resumen Técnico. In: Cambios Climáticos 2007: Base Física de la Ciencia. Aportes del Grupo de Trabajo I al Cuarto Informe de Evaluación del Panel Intergubernamental sobre Cambios Climáticos. Cambridge, Reino Unido y Nueva York, NY, Estados Unidos: Cambridge University Press, 2007.

STERN, N. et al.. The Economics of Climate Change: The Stern Review. British Government. 2006. Disponível em: <mudancasclimaticas.cptec. inpe.br/ rmclima/pdfs/sternreview_report complete.pdf >. Acesso em: 24 fev. 2009.

SUGUIO et al. Mudanças climáticas, ceticismo e dogmatismo. A Grande Farsa do Aquecimento Global. Disponível em: < http://agfdag.wordpress. com $/ 2012 / 08 / 26 /$ mudancas-climaticas-ceticismo-e-dogmatismo/>. Acesso: 08 nov. 2012.

TRENBERTH, K. E. et al. Observations: Surface and Atmospheric Climate Change. In: Climate Change 2007: The Physical Science Basis. Contribution of Working Group I to the Fourth Assessment Report of the Intergovernmental Panel on Climate Change. Solomon, S., D. Qin, M. Manning, Z. Chen, M. Marquis, K.B. Averyt, M. Tignor and H.L. Miller (eds.). Cambridge, United Kingdom and New York, NY, USA: Cambridge University Press, 2007.

UNITED NATIONS ENVIRONMENT PROGRAMME (UNEP). The Emissions Gap Report 2012: A UNEP Synthesis Report. Disponível em: $<$ http://www.unep.org/pdf/2012gapreport.pdf $>$. Acesso em: 23 nov. 2012.

WORLD METERIOLOGICAL ORGANIZATION (WMO). Global Atmosphere Watch. 2012. Disponível em: < http://www.wmo.int/pages/prog/ arep/gaw/gaw home en.html>. Acesso em 20 nov. 2012.a

Wmo Greenhouse Gas Bulletin. The State of Greenhouse Gases in the Atmosphere Based on Global Observations through 2011. $\mathrm{N}^{\circ} .8,19$ nvember 2012. Disponível em: <http://www.wmo.int/pages/ mediacentre/press releases/documents/GHG_Bulletin No.8 en.pdf>. Acesso em: 23 nov. 2012.b 